\title{
Avaliação de progresso do Programa Nacional de Cooperação Acadêmica - Novas Fronteiras - edição 2007 e oportunidades de formação de redes cooperativas nas áreas estratégicas e tecnologias portadoras de futuro
}

DAYSE BENIGNA BERNARDO ARAUJO GOMES Coordenação de Aperfeiçoamento de Pessoal de Nivel Superior

IVAN ROCHA NETO

Universidade Católica de Brasília

\section{INTRODUÇÃO E CONTEXTO}

Até a primeira metade do século XX, a ciência evoluiu quase exclusivamente com base na produção de pesquisadores individuais e com baixa intensidade de cooperação. Uma grande mudança no ambiente científico tem sido a formação de redes cooperativas para desenvolver temas de investigação mais complexos, que requerem complementaridade de competências.

Ao mesmo tempo, o Brasil tem sido desafiado a realizar pesquisas orientadas ao desenvolvimento das tecnologias portadoras de futuro (Biotecnologia, Nanotecnologia e Tecnologia da Informação e Comunicação) e nas áreas estratégicas (Engenharias, Energias, Saúde, Meio Ambiente e Recursos do Mar), voltadas à redução das disparidades acadêmicas regionais. Essas áreas e tecnologias são apresentadas no Livro Azul da Quarta Conferência Nacional de Ciência, Tecnologia e Inovação para o Desenvolvimento Sustentável (4a CNCTI), realizada em 2010.

Além disso, há necessidade de criação de condições mais favoráveis à fixação de pesquisadores qualificados nas regiões menos atrativas do ponto de vista acadêmico, o que reforça a necessidade de formação de redes cooperativas de pós-graduação e pesquisa no campo do conhecimento científico e tecnológico. 
O reconhecimento dessa realidade estimulou a Coordenação de Aperfeiçoamento de Pessoal de Nível Superior (CAPES) a apoiar a criação de redes para formação de grupos com competências mais diversificadas e complementares, desenvolvendo vários programas com esse propósito, dentre os quais o Programa Nacional de Cooperação Acadêmica - Novas Fronteiras (PROCAD NF).

Embora os projetos sejam regularmente avaliados, há ainda necessidade de sistematização metodológica e escolha de indicadores para estender o processo à avaliação do programa como estratégia de fomento, de acordo com as motivações que lhes deram origem.

Este artigo tem o propósito de apresentar as conclusões da avaliação de progresso e mostrar os resultados obtidos até 2010, do Programa Nacional de Cooperação Acadêmica, na ação Novas Fronteiras, edição de 2007. Essa avaliação foi orientada para levantar os resultados parciais, pois essa fase ainda não foi concluída e, portanto, sua eficácia e efetividade não poderiam ser avaliadas no momento. Além disso, os autores consideraram relevante identificar oportunidades de formação de redes cooperativas de pesquisa e pós-graduação relacionadas às tecnologias portadoras de futuro e às áreas estratégicas, com o propósito de redução das disparidades acadêmicas regionais, inclusive para servir de base à continuidade deste estudo.

A metodologia para identificação das oportunidades de formação de redes de pós-graduação e pesquisa partiu da escolha de palavras-chave relacionadas às áreas estratégicas e tecnologias portadoras de futuro, mediante cruzamento das ocorrências no Diretório Nacional dos Grupos de Pesquisa do Conselho Nacional de Desenvolvimento Científico e Tecnológico (DGP/CNPq), que apresenta os cadastros dos grupos de pesquisa em atividade no país, com as informações de cursos e programas recomendados pela CAPES, com nota igual ou superior a cinco ou com potencial para liderar a formação de redes.

\section{POTENCIAL DE FORMAÇÃO DE REDES DE PESQUISA E PÓS-GRADUAÇÃO: FUNDAMENTOS}

A colaboração científica em rede compreende um empreendimento cooperativo que envolve interesses comuns e resultados, com responsabilidades e méritos compartilhados de acordo com Balancieri et al. (2005). Assim, essa forma de organização da ciência enseja oportunidades para intensificar a produção científica e a formação de pessoal qualificado. Ganhos importantes podem resultar da formação de redes de cooperação científica quando comparados aos resultados obtidos por grupo de pesquisadores isolados, além da ampliação do repertório de metodologias e estratégias de investigação, com base na fertilização cruzada de ideias entre grupos distintos. Para Weisz e Roco (1996), cada vez mais o avanço científico depende de esforços coletivos e da formação de redes cooperativas de pesquisa. 
A produção de artigos em coautoria tem sido um dos principais indicadores de resultados da colaboração entre grupos de pesquisadores, conforme demonstrado empiricamente por Price (1963), que forneceu evidências do aumento de autorias múltiplas na ciência.

Storer (1970) afirma que a investigação por meio das técnicas bibliométricas é responsável pelo que se sabia sobre a colaboração científica. Destaca, sobretudo, que cada área do conhecimento tem características cognitivas e organizacionais próprias, alterando, assim, o grau de cooperação. Como exemplo, aponta que as Ciências Básicas e as Ciências Naturais apresentam um maior índice de cooperação do que as Ciências Aplicadas e as Ciências Sociais.

Beaver e Rosen (1979), citados por Balancieri et al. (2005, p. 66), afirmaram que, considerando a pluralidade de colaborações que podem ser estabelecidas entre grupos de interesses, "não é de se estranhar que as razões que levam os cientistas a colaborar entre si sejam também das mais diferentes naturezas". A mais contundente, para esses autores, é a necessidade da contribuição especializada de outros grupos de pesquisadores, interessados em objetos comuns de investigação, o que também inclui a aprendizagem de novos conhecimentos e habilidades por meio da formação de pessoal qualificado, fato típico das relações entre mestres e estudantes.

A integração entre os pesquisadores é a motivação da cooperação, mesmo que nas pesquisas de rotina ou na formulação de ideias mais complexas. Essas interações possuem distintos níveis de intensidade, variando de acordo com os interesses dos cooperantes na busca comum por resultados, análises, discussões ou propostas acerca de temas afins. A cooperação entre pesquisadores, como aponta Subramanyam (1983), gera impactos significativos que vão além da discussão informal. Tais colaborações, obtidas por meio da integração entre pesquisadores de diferentes ambientes científicos, estimulam a produção de artigos em coautoria, o que, por fim, mantém viva a colaboração.

O mesmo estudo demonstra que a contagem de artigos realizados em coautoria tem sido a medida mais comumente usada para detectar a ocorrência e a abrangência de colaborações científicas. Esse indicador é válido para avaliação de progresso do Programa Nacional de Cooperação Acadêmica - Novas Fronteiras, objeto desta pesquisa, assim como à formação de mestres e doutores para fixá-los nas regiões distantes dos centros acadêmicos mais dinâmicos.

Um fator preponderante, motivador da colaboração científica, tem sido a intensificação de linhas de pesquisa interdisciplinares, como são, em geral, as incluídas nas áreas estratégicas e nas bases científicas das tecnologias portadoras de futuro. Alguns dos mais significativos avanços científicos surgiram da interação entre áreas de investigação anteriormente separadas, como, por exemplo, mecatrônica, que envolve conhecimentos de eletrônica, informática, mecânica e automação. 
As colaborações são também motivadas pela redução dos custos das pesquisas mediante uso compartilhado de equipamentos e outros itens de infraestrutura. Importante destacar, ainda, que a formação de redes cooperativas de pesquisa e pós-graduação enseja elevado potencial para o desenvolvimento de projetos interinstitucionais, conforme proposto por Gatti (2004) e constante dos depoimentos dos coordenadores consultados nessa pesquisa. $\mathrm{O}$ processo de formação de redes cooperativas de pesquisa e pós-graduação tem contribuído para a melhoria do desempenho dos grupos envolvidos, não somente para o fortalecimento da pesquisa ou para a criação de novos programas de pós-graduação. Ao mesmo tempo, tais redes propiciam o aumento da produção científica.

A atual gestão da CAPES tem adotado três princípios para criação e gestão de seus programas: qualidade, relevância e flexibilidade. Nesse sentido, o futuro do sistema de avaliação será objeto de grandes mudanças que já estão em gestação, orientadas mais para os resultados do que para a existência de condicionantes de pessoal, infraestrutura e de outros insumos.

Segundo Reinaldo Guimarães (2007), essas mudanças envolvem os seguintes aspectos: elevação da capacidade de indução e de execução de políticas de educação, ciência, tecnologia e inovação, agregando aos critérios de mérito científico outros relacionados à relevância, segundo a demanda de outros agentes para efeito de seleção e financiamento de projetos com potencial para introdução de inovações tecnológicas e redução de desequilíbrios regionais. O referido autor também apontou, entre outros aspectos, a necessidade de abertura da pós-graduação para além das fronteiras da educação superior, no intuito de desenvolver temas de pesquisa de acordo com as demandas do país, além de qualificar pessoal para manutenção e expansão.

Ao mesmo tempo, no que se refere à taxonomia das áreas de avaliação, quase exclusivamente determinadas pelas disciplinas científicas (física, química, biologia e sociologia) e profissionais, como saúde, direito e engenharias, é necessário incluir os cortes tecnológicos (nanotecnologia, biotecnologia, tecnologia da informação e comunicação, mecatrônica e robótica), bem como temas interdisciplinares como energia e meio ambiente, entre outros. Assim, envolve uma matriz complexa de distintas formas de organização do conhecimento científico e tecnológico e formação de grupos de pesquisa. Novos critérios e indicadores devem ser concebidos e aplicados para solucionar tais cortes.

\section{O PROGRAMA NACIONAL DE COOPERAÇÃO ACADÊMICA - NOVAS FRONTEIRAS}

O Programa Nacional de Cooperação Acadêmica - Novas Fronteiras tem por objetivo apoiar o desenvolvimento de projetos conjuntos de ensino e pesquisa em instituições distintas, que estimulem a formação pós-graduada, a mobilidade 
docente e discente, bem como a fixação de doutores nas regiões Norte, Nordeste e Centro-Oeste. O Programa atende ao proposto no Plano Nacional de Pós-Graduação - 2005-2010 (PNPG), que prevê ações visando à diminuição das desigualdades acadêmicas regionais e intrarregionais, observadas no Sistema Nacional de Pós-Graduação (SNPG). São elegíveis aos benefícios do Programa as Instituições de Ensino Superior (IES), públicas e privadas, localizadas nas regiões Norte, Nordeste e Centro-Oeste, que oferecem programas de pós-graduação avaliados e recomendados pela CAPES.

Graças a esse esforço ao longo dos últimos anos, o SNPG evoluiu em qualidade e diversidade, no intuito de responder às necessidades de conhecimento técnico-científico para solução de problemas de interesse regional e nacional.

O Programa Nacional de Cooperação Acadêmica foi instituído em 2000, visando melhorar a eficiência do sistema quanto ao aproveitamento de pessoal qualificado, assim como a infraestrutura disponível para reduzir os desequilíbrios acadêmicos regionais e promover a expansão e a melhoria da qualidade do sistema de pós-graduação nas diversas áreas do conhecimento. O Programa estimula a formação de parcerias entre instituições com programas de excelência com outras ainda em evolução para criação de novos programas, por meio da realização de missões de estudo, pesquisa e docência e estágio pós-doutoral, possibilitando a interação entre as equipes e consolidando as redes de cooperação.

A primeira chamada do Programa, em 2000, foi uma experiência piloto que apoiou 33 projetos. Nessa edição, o investimento realizado foi da ordem de $\mathrm{R} \$ 7$ milhões, distribuídos para 78 equipes. Para a edição de 2001, a CAPES investiu aproximadamente $\mathrm{R} \$ 20$ milhões em 86 projetos e inovou, introduzindo duas modalidades de projetos de cooperação: entre equipes - sendo uma denominada líder, vinculada a programa de doutorado com nota igual ou superior a cinco, e outras associadas - constituídas por pesquisadores, estudantes e técnicos de outra instituição para criação de programas de pós-graduação, com duração de quatro anos, com setenta projetos apoiados; e entre equipes vinculadas a cursos de doutorado avaliados com nota igual ou superior a cinco, apoiando 16 projetos, com duração de dois anos, formando, assim, 281 equipes.

Em 2003, a partir de visitas aos projetos, foi realizada uma avaliação por uma comissão julgadora, que confirmou a importância do programa para a pós-graduação, com a constatação de que essa forma de fomento facilita o desenvolvimento das pesquisas mais complexas e intensifica a interação entre os grupos apoiados. Com base nesses resultados, foram lançados mais dois editais, com abrangência nacional. O edital de 2005 contou com um investimento da ordem de $\mathrm{R} \$ 32$ milhões para quatro anos de execução, beneficiando 337 equipes, distribuídas em 132 projetos, envolvendo 81 instituições. E, em 2007, resultando na formação de 563 equipes de 127 instituições, com investimentos aproximados de $\mathrm{R} \$ 50$ milhões, distribuídos em 207 projetos. 
De acordo com Jorge Guimarães (2008), para fixação do pesquisador em sua própria região, é preciso criar ambiência favorável ao desenvolvimento de projetos para evitar a migração de pesquisadores doutores para as regiões mais desenvolvidas, principalmente para o Sudeste. Nessa perspectiva, com o intuito principal de reduzir essas desigualdades regionais, a CAPES criou a modalidade Novas Fronteiras, especificamente voltada à Amazônia, possibilitando, além da abordagem de novos tópicos de pesquisa, criar condições mais favoráveis para fixação de pesquisadores doutores, tanto nessa região quanto no Nordeste e Centro-Oeste. O PROCAD Amazônia, lançado em 2006, apoiou 28 projetos de pesquisa, viabilizando a interação entre 34 instituições. Foram investidos pouco mais de $\mathrm{R} \$ 6$ milhões na única seleção de projetos.

No ano seguinte, a CAPES lançou a modalidade Novas Fronteiras, priorizando áreas temáticas específicas, como ciências agrárias; ecologia e meio ambiente; biotecnologia; engenharias; computação; ensino de ciências e matemática; saúde coletiva, para as regiões Centro-Oeste, Norte e Nordeste, com apoio a 82 projetos, envolvendo 185 equipes de 67 instituições, com investimentos da ordem de $\mathrm{R} \$ 32$ milhões. O Quadro 1 resume os investimentos realizados pelo PROCAD no período 2000-2009.

Quadro 1 - Investimentos PROCAD (2000-2009)

\begin{tabular}{|c|c|c|c|c|}
\hline Edição & Edital & $\begin{array}{c}\text { Investimentos } \\
\text { (Milhões/R\$) }\end{array}$ & Equipes & Projetos \\
\hline 2000 & PROCAD Nacional & 7 & 78 & 33 \\
\hline 2001 & PROCAD Nacional & 20 & 281 & 86 \\
\hline 2005 & PROCAD Nacional & 32 & 337 & 132 \\
\hline 2006 & PROCAD Amazônia & 6 & 56 & 28 \\
\hline 2007 & PROCAD Nacional & 50 & 563 & 207 \\
\hline 2007 & Novas Fronteiras & 32 & 185 & 82 \\
\hline 2008 & Novas Fronteiras & 34 & 227 & 110 \\
\hline 2009 & Novas Fronteiras & 36 & 325 & 136 \\
\hline
\end{tabular}

Elaboração do autor.

Fonte: Dados PROCAD/CAPES.

*Valores aproximados.

Desse modo, o Programa tem estimulado não somente a produção científica, mas também a disseminação e apropriação de conhecimentos por meio da cooperação, estimulando a criação de novos programas de pós-graduação, como também consolidando os já existentes, contribuindo para a redução dos desequilíbrios acadêmicos regionais e intrarregionais. 
A resposta da execução desse Programa mostrou-se tão positiva que a comunidade científica induziu a CAPES a realizar outras duas edições. Em 2008, com uma maior abrangência temática, com 110 projetos, 227 equipes, envolvendo 79 instituições. Essa edição conta com recursos da ordem de $\mathrm{R} \$ 34$ milhões. Em 2009, haja vista os excelentes indicadores que possibilitaram a terceira edição do edital, 136 projetos foram aprovados, formando 325 equipes de 87 instituições. Os investimentos previstos para essa edição somam um montante aproximado de $\mathrm{R} \$ 36$ milhões.

Das considerações anteriores, foi possível identificar os principais indicadores adotados para efeitos de avaliação de progresso e dos resultados do Programa.

\section{AVALIAÇÃO DE PROGRESSO, METODOLOGIA E DISCUSSÃO DOS RESULTADOS DA EDIÇÃO NF 2007}

Foi criado um instrumento de consulta, remetido aos coordenadores de projetos da Edição NF 2007, para avaliação de progresso do ponto de vista dos executores, isso em comparação com os pareceres da comissão julgadora, quando da Avaliação Intermediária dos projetos em andamento, que recomendou a renovação de 73 projetos dos 82 avaliados. A Avaliação Intermediária é prevista nos editais do PROCAD, sendo que a cada dois anos são apresentados relatórios consolidados das atividades realizadas, objeto de análise para determinação da continuidade dos projetos.

O instrumento de consulta foi simples e com base na linguagem e nos requisitos de informações dos relatórios de desempenho enviados anualmente à CAPES pelos coordenadores de projetos. Entretanto, foi submetido à validação de um pequeno número de coordenadores em relação ao entendimento das questões. A consulta envolveu quesitos de natureza quantitativa e qualitativa, para investigar sobre as percepções dos coordenadores, cujos resultados são mostrados no Quadro 2. 


\section{Quadro 2 - Resultados da Consulta}

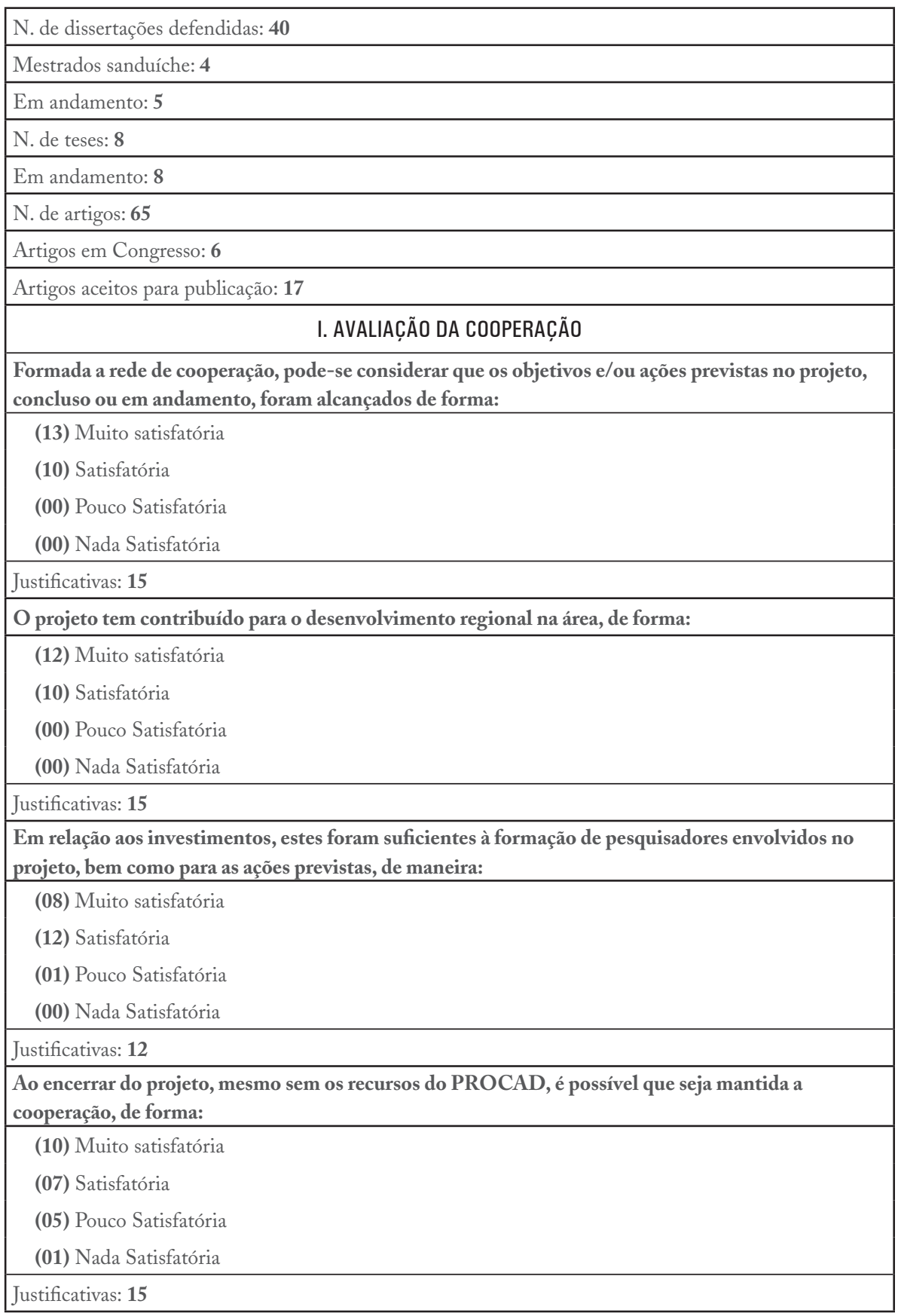

Elaboração do autor.

Fonte: Pesquisa com coordenadores. 
A amostra foi composta de 23 respondentes, dos 73 projetos que tiveram continuidade recomendada pela Comissão Julgadora, de um total de 82 projetos avaliados, portanto, cerca de $32 \%$ dos recomendados responderam à consulta.

A presente avaliação de progresso, considerando que a edição do referido Programa ainda está em andamento, valorizou os processos, pois uma parcela dos projetos não tiveram a possibilidade de apresentar resultados expressivos, conforme é demonstrado nas observações qualitativas. Portanto, não é possível, nesse momento, avaliar a eficácia ou efetividade do Programa. Os resultados, quanto à produção de artigos publicados em revistas ou congressos e aceitos para publicação, além da produção de dissertações, foram expressivos e compatíveis com o tempo de execução do Programa, nessa edição, embora a comissão julgadora tenha recomendado a intensificação da produção científica, em boa parte dos projetos, bem como a elevação da qualidade dos periódicos que têm sido escolhidos para divulgação dos resultados.

Com relação aos projetos de pós-doutorado, segundo os respondentes, os resultados mostraram-se insatisfatórios ou não foram devidamente registrados nos relatórios e nos questionários.

Ao mesmo tempo, a avaliação qualitativa permitiu obter informações referentes às considerações dos coordenadores com relação ao progresso de seus projetos, indicando que 13/23 (aproximadamente 57\%) se mostraram muito satisfeitos com os resultados da cooperação, e $43 \%$ satisfeitos. Nesse quesito, não houve manifestação negativa de nenhum dos respondentes. Além disso, 15/23, ou cerca de $65 \%$, apresentaram justificativas para suas respostas, indicando maior fundamentação para suas interpretações.

Com relação à contribuição para o desenvolvimento regional, doze coordenadores responderam estar muito satisfeitos, e o restante (10/23) declarou-se satisfeito. Um dos coordenadores não respondeu a esse quesito, pois considerou que seu projeto não tem esse objetivo. Analogamente, na mesma proporção (68\%), as respostas foram justificadas.

$\mathrm{Na}$ questão relativa à suficiência dos investimentos, dois coordenadores não responderam a questão, indicando que não formaram opinião sobre esse quesito, provavelmente pelo parcial cumprimento das metas, sendo que oito consideraram muito satisfatória e doze satisfatória. Conforme a avaliação do relatório consolidado, procedido após dois anos de execução do Programa, realizada pela comissão julgadora, ocorreram casos que apresentaram saldo financeiro remanescente, confirmando o atraso observado no desenvolvimento de alguns projetos. A maioria das justificativas apresentadas pelos executores dos projetos percebem esse atraso, não o relacionando à omissão na execução das atividades, mas sim à impossibilidade de adequação da agenda dos participantes com o planejamento contido nos projetos.

Com relação às possibilidades de continuidade ou sustentabilidade da cooperação, sem apoio da CAPES, 6/23, cerca de 27\%, consideram pouco a nada satisfatória, demonstrando forte dependência de recursos da CAPES para sustentação 
da cooperação. Ressalte-se que 10/23 (43\%) consideraram que a cooperação será muito satisfatoriamente mantida e 30\% satisfatoriamente. Responderam a esse tópico $60 \%$, indicando insegurança por parte dos executores com relação à continuidade da cooperação, sendo que, se retirado o apoio da CAPES, a continuidade na cooperação entre equipes de diferentes locos será profundamente, ou definitivamente, abalada. Essa constatação foi confirmada pelas sugestões de continuidade encontradas no espaço aberto para sugestões.

\section{DISTRIBUIÇÃO TEMÁTICA}

Com relação à distribuição temática dos projetos respondentes da consulta, pode-se verificar um bom equilíbrio entre as distintas áreas, embora tenha havido uma maior proporção de projetos classificados nas ciências agrárias, mas com grande diversidade de objetos de investigação, conforme demonstrado no Quadro 3. Não obstante, praticamente todos os projetos foram considerados relevantes para o desenvolvimento regional.

\section{Quadro 3 - Distribuição de Projetos, por Área de Conhecimento}

\begin{tabular}{|c|c|c|}
\hline Grande Área & Área de Conhecimento & $\mathrm{N}^{0}$ Projetos \\
\hline \multirow{7}{*}{ Ciências Agrárias } & Melhoramento Vegetal & 1 \\
\hline & Produção Animal & 1 \\
\hline & Ciência do Solo & 2 \\
\hline & Irrigação e Drenagem & 1 \\
\hline & Fitotecnia & 1 \\
\hline & C\&T de Alimentos & 2 \\
\hline & Agronomia & 2 \\
\hline Ciências da Saúde & Farmácia & 1 \\
\hline \multirow{2}{*}{$\begin{array}{c}\text { Ciências Exatas } \\
\text { e da Terra }\end{array}$} & Ciência da Computação & 1 \\
\hline & Química & 1 \\
\hline \multirow{5}{*}{ Engenharias } & Engenharia Civil & 2 \\
\hline & Engenharia de Materiais & 3 \\
\hline & Engenharia Química & 1 \\
\hline & Engenharia Mecânica & 2 \\
\hline & Engenharia Elétrica & 1 \\
\hline Multidisciplinar & Biotecnologia & 1 \\
\hline \multicolumn{2}{|c|}{ Total de projetos que responderam a } & 23 \\
\hline
\end{tabular}

Elaboração do autor.

Fonte: Dados PROCAD/CAPES. 


\section{AVALIAÇÃO DA COMISSÃO DE ESPECIALISTAS}

$\mathrm{Na}$ apreciação geral dos pareceres, elaborados pelos participantes da comissão julgadora, a qual recomendou a renovação de 73 projetos dos $82 \mathrm{em}$ andamento, a maioria dos projetos apresentou saldo financeiro remanescente, apesar de terem cumprido parte representativa das metas propostas. Esse saldo dos projetos, não utilizado, oriundo dos dois primeiros anos (2008 e 2009), foi remanejado com autorização formal da CAPES, sendo transferido e, automaticamente, somado ao repasse do terceiro ano (2010). Em alguns casos, foi verificada lentidão no cumprimento das metas previstas, mas mesmo assim foram recomendadas as renovações, considerando as circunstâncias e a relevância dos projetos.

O Quadro 4, a seguir, apresenta a distribuição dos projetos em andamento, no âmbito dessa ação Novas Fronteiras 2007. São 46 projetos para o Nordeste, 15 para o Centro-Oeste e 12 para a região Norte. Com relação a esta última, importa destacar que há outros 27 projetos ativos do PROCAD Amazônia, desenvolvidos a partir de 2006, conforme o PNPG (2005-2010). Para efeitos desse Programa, além dos estados da região Norte (Acre, Amapá, Amazonas, Pará, Rondônia, Roraima e Tocantins), compreende a ação os estados do Maranhão e Mato Grosso, formando assim, o território da Amazônia Brasileira.

\section{Quadro 4 - Distribuição de projetos por região (total de projetos renovados)}

\begin{tabular}{|l|c|}
\hline \multicolumn{1}{|c|}{ Regiões } & Instituições Proponentes \\
\hline Norte & 13 \\
\hline Nordeste & 46 \\
\hline Centro-Oeste & 14 \\
\hline Total & 73 \\
\hline
\end{tabular}

Elaboração do autor.

Fonte: Dados PROCAD/CAPES.

O Quadro 5 mostra a distribuição dos projetos recomendados pela CAPES por área de avaliação. Para continuidade, tem-se 73 projetos distribuídos entre vinte áreas distintas. Como áreas beneficiadas do PROCAD NF 2007 aparecem, com mais representatividade, as ciências agrárias, com 19 projetos; engenharias, com 18; interdisciplinar, zootecnia e recursos pesqueiros, com seis projetos cada; ciências biológicas e ensino de ciências e matemática, com quatro projetos respectivos para cada uma dessas áreas. 
Quadro 5 - Distribuição de projetos para continuidade, por área de avaliação

\begin{tabular}{|l|c|}
\hline \multicolumn{1}{|c|}{$\begin{array}{c}\text { Projetos Aprovados pela CAPES para Continuidade } \\
\text { (por Área de Avaliação) }\end{array}$} & N. Projetos \\
\hline Biotecnologia & 1 \\
Ciência da Computação & 2 \\
Ciência de Alimentos & 3 \\
Ciências Agrárias & 19 \\
Ciências Biológicas (I, II, III) & 4 \\
Ecologia e Meio Ambiente & 3 \\
Engenharia I & 4 \\
Engenharia II & 5 \\
Engenharia III & 6 \\
Engenharia IV & 3 \\
Ensino de Ciências e Matemática & 4 \\
Interdisciplinar & 6 \\
Medicina II & 1 \\
Medicina Veterinária & 3 \\
Química & 1 \\
Química Orgânica & 1 \\
Saúde Coletiva & 1 \\
Zootecnia e Recursos Pesqueiros & 6 \\
\hline Total de Projetos recomendados para continuidade & 73 \\
\hline
\end{tabular}

Elaboração do autor.

Fonte: Dados PROCAD/CAPES.

No Quadro 6, a distribuição de projetos entre as instituições, em cada região, pode ser considerada equilibrada e compatível com o potencial das instituições contempladas. 


\section{Quadro 6 - Distribuição de Projetos, por Instituição Proponente}

\begin{tabular}{|c|c|}
\hline Região, Siglas e Identificação das Instituições Proponentes & Projetos \\
\hline Nordeste & 46 \\
\hline Universidade Estadual do Oeste da Bahia- UESB & 2 \\
\hline Universidade Estadual de Santa Cruz - UESC & 2 \\
\hline Universidade Federal de Alagoas - UFAL & 3 \\
\hline Universidade Federal da Bahia - UFBA & 3 \\
\hline Universidade Federal do Ceará - UFC & 4 \\
\hline Universidade Federal de Campina Grande - UFCG & 3 \\
\hline Universidade Federal do Semi-Árido - UFERSA & 2 \\
\hline Universidade Federal da Paraíba - UFPB & 2 \\
\hline Universidade Federal de Pernambuco - UFPE & 3 \\
\hline Universidade Federal do Recôncavo Baiano - UFRB & 2 \\
\hline Universidade Federal do Rio Grande do Norte - UFRN & 4 \\
\hline Universidade Federal Rural de Pernambuco - UFRPE & 6 \\
\hline Universidade Federal de Sergipe - UFSE & 3 \\
\hline Universidade Católica de Pernambuco - UNICAP & 2 \\
\hline Universidade de Salvador - UNIFACS & 1 \\
\hline Universidade de Fortaleza - UNIFOR & 1 \\
\hline Universidade Tiradentes - UNIT & 2 \\
\hline Universidade Estadual de Pernambuco - UPE & 1 \\
\hline Norte & 13 \\
\hline Instituto de Pesquisa da Amazônia - INPA & 1 \\
\hline Universidade Federal do Acre - UFAC & 3 \\
\hline Universidade Federal do Amazonas - UFAM & 3 \\
\hline Universidade Federal do Pará - UFPA & 2 \\
\hline Universidade Federal Rural da Amazônia - UFRA & 1 \\
\hline Universidade Federal do Tocantins - UFT & 1 \\
\hline Universidade Federal de Rondônia - UNIR & 1 \\
\hline Universidade Federal do Amapá - UNIFAP & 1 \\
\hline Centro-Oeste & 15 \\
\hline Universidade Católica Dom Bosco - UCDB & 1 \\
\hline Universidade Católica de Goiás - UCG & 2 \\
\hline Universidade Estadual de Goiás - UEG & 2 \\
\hline Universidade Federal de Goiás - UFG & 2 \\
\hline Universidade Federal de Grande Dourados - UFGD & 2 \\
\hline Universidade Federal de Mato Grosso do Sul - UFMS & 2 \\
\hline Universidade Federal do Mato Grosso - UFMT & 2 \\
\hline Universidade de Brasília - UnB & 2 \\
\hline Total de Projetos por IES Proponente & 73 \\
\hline
\end{tabular}

Elaboração do autor.

Fonte: Dados PROCAD/CAPES. 


\section{CRÍTICAS E SUGESTÕES}

Dos 23 respondentes à consulta, dois apresentaram críticas em relação à necessidade de maior flexibilidade operacional para pagamento de pró-labore aos pesquisadores visitantes, ainda que estes, conforme norma do edital, já recebam diárias e passagens pelo período em que permanecerem na IES de destino (local de execução das atividades docentes). Observa-se, nesse sentido, que nenhuma das edições do PROCAD permite o pagamento de pró-labore, obedecendo à Instrução Normativa 1/97 para os editais PROCAD, cujas edições datem até o ano de 2007 e à Portaria Interministerial 127/2008 para as edições posteriores. Ao mesmo tempo, vários foram os elogios ao Programa e suas diretrizes e ao desempenho da CAPES no atendimento às demandas dos projetos. Dentre as sugestões, destacaram-se as seguintes:

- Manter o Programa, permitindo a continuidade dos projetos entre as edições, sem necessidade de nova candidatura, com a finalidade da consolidação da cooperação estabelecida entre as equipes, na busca da evolução de pesquisas com maior grau de complexidade;

- Permitir a participação de bolsistas para a realização de estágios sanduíche de períodos diferentes ao estabelecido no edital do Programa (30 dias), mantendo o valor do auxílio-moradia na faixa dos $50 \%$ referentes ao valor da bolsa estipulada para cada modalidade. A solicitação deve-se ao fato de que, para alguns coordenadores, os alunos não têm condições, em sua maioria, de permanecerem afastados de sua IES de origem por período superior a 15 dias;

- Aumentar o valor do auxílio-moradia para piso superior a $50 \%$ do valor da bolsa estipulada para cada modalidade;

- Permitir que as equipes do PROCAD NF possam constituir-se de quatro instituições, sendo uma proponente (principal) e outras três associadas. Segundo os respondentes, isso aumentaria a conectividade e a produtividade dos trabalhos em cooperação;

- Promover a revisão dos valores regionalmente predeterminados das diárias a serem recebidas, quando da realização de missões de pesquisa e docência em outras localidades. Cabe esclarecer que esses valores são estabelecidos por meio de decreto aos servidores públicos federais, incluindo-se aí os pesquisadores de instituições privadas, e não por determinação da CAPES. Os valores das diárias, em vigor, foram determinados pelo Decreto n. 6.907/2009;

- Permitir o aumento da rubrica Parcela Fixa (Custeio) para montante superior a R $\$ 10$ mil, conforme estipula o Edital PROCAD NF, e que esse montante se destine não apenas à aquisição de material de consumo, como itens de papelaria e pequenos reparos, mas que seja permitida a aquisição de itens a serem patrimoniados, a exemplo de equipamentos laboratoriais e acervo bibliográfico. 


\section{MAPEAMENTO DAS OPORTUNIDADES DE FORMAÇÃO DE REDES}

O propósito dessa pesquisa não foi indicar quais devem ser as opções da CAPES para o futuro do Programa, mas apenas apresentar o mapeamento de oportunidades de indução para formação de redes cooperativas mais amplas no âmbito do Programa PROCAD NF, indicando possibilidades de desenvolvimento das tecnologias portadoras de futuro e áreas estratégicas, ao mesmo tempo relevantes para o desenvolvimento regional. Importa esclarecer que as escolhas temáticas não são exaustivas nem exclusivas, podendo ser completadas mediante realização de estudos prospectivos mais abrangentes e detalhados.

A Quarta Conferência Nacional de Ciência, Tecnologia e Inovação ( $4^{a} \mathrm{CNC}-$ TI, 2010) considera as áreas que compõem as tecnologias portadoras de futuro como aquelas que ampliam o acesso e reduzem a exclusão de pessoas de todas as classes. Por sua vez, os estudos prospectivos desenvolvidos pelo CGEE (2010) e pela CAPES (2009) em relação ao potencial de expansão da pós-graduação apontam as engenharias e as fontes de energia limpa (nuclear, solar, eólica, bioenergia e células combustíveis) como as que emitem menos ou nenhuma quantidade de $\mathrm{CO}_{2}$, além de outros temas de pesquisa emergentes, importantes para o desenvolvimento sustentável do país.

A $4^{a}$ CNCTI destacou, ainda, a importância da contribuição de áreas como agricultura, bioenergia e tecnologia da informação e comunicação, entre outras fontes de energia limpa, para a construção do padrão de desenvolvimento sustentável.

Quanto a essa contribuição, as ciências agrárias são consideradas como a de maior impacto na produção científica e tecnológica do país e seu desenvolvimento tem sido atribuído à consolidação dos programas de pós-graduação e ao papel da Empresa Brasileira de Pesquisa Agropecuária (EMBRAPA) no cenário nacional e internacional, bem como à recuperação das instituições estaduais de pesquisa agropecuária. Outras contribuições relevantes estão voltadas para a produção de alimentos (terceiro maior produtor mundial) e participação na geração de divisas por meio da exportação de matérias-primas e viabilização da bioenergia. Além disso, é preciso destacar que o Brasil tem claro potencial para consolidar sua liderança mundial na área de biocombustíveis com a produção de etanol.

Em relação à saúde, seu complexo econômico e industrial, com ênfase no segmento farmacêutico, precisa orientar-se mais intensamente para resolver as necessidades do país e substituir o emprego de princípios ativos importados por outros países pelos que possam ser explorados da biodiversidade brasileira.

Nesse contexto, as recentes descobertas do Pré-Sal abrem novas possibilidades de desenvolvimento científico e tecnológico, além da formação de redes cooperativas de pós-graduação e pesquisa.

Especificamente em relação à Amazônia, as demandas e sugestões da Conferência apontam para a necessidade de redução do desequilíbrio regional e para melhor exploração da biodiversidade da região. 
Desse modo, as seguintes oportunidades (não exaustivas) de formação de redes nas áreas estratégicas e tecnologias portadoras de futuro, envolvendo instituições do Norte, Nordeste e Centro-Oeste, foram identificadas com base nos cruzamentos das ocorrências no DGP/CNPq, e dos cursos recomendados pela CAPES em áreas selecionadas, de acordo com a maior incidência de pesquisas nos temas investigados, com nota igual ou superior a cinco, na última avaliação trienal.

Os quadros seguintes mostram oportunidades de formação de redes de pesquisa e pós-graduação nos temas estratégicos investigados, envolvendo instituições das regiões Norte, Nordeste e Centro-Oeste, destacando-se as tecnologias portadoras de futuro (nanotecnologia, biotecnologia, tecnologia da informação e comunicação, energia e as tecnologias ambientais).

Nesse sentido, foram identificadas 209 ocorrências de grupos de pesquisa relacionados à nanotecnologia em todas as áreas, sendo que apenas seis envolvem programas de pós-graduação em engenharia química e engenharia de materiais, que na relação de cursos recomendados pela CAPES tiveram nota igual ou superior a cinco e que poderiam liderar redes PROCAD NF, conforme demonstrado a seguir. O tema nanotecnologia foi também explorado nas engenharias, saúde, ciências biológicas e ciências exatas e da terra.

\section{Quadro 7 - Consolidado para Nanotecnologia}

\begin{tabular}{|l|c|c|c|}
\hline \multicolumn{1}{|c|}{ Grande Área } & $\begin{array}{c}\text { Área de Avaliação da } \\
\text { CAPES }\end{array}$ & $\begin{array}{c}\text { N. de Programas } \\
\text { com Conceito Igual } \\
\text { ou Superior a 5 }\end{array}$ & IES \\
\hline Engenharias & $\begin{array}{c}\text { Engenharia Química e } \\
\text { Engenharia de Materiais }\end{array}$ & 6 & $\begin{array}{c}\text { UFRJ, UFSC, USP, } \\
\text { UNICAMP, UFRG, } \\
\text { UFMG }\end{array}$ \\
\hline Ciências da Saúde & Farmácia & 2 & UFRGS, UNESP/Ar \\
\hline Ciências Agrárias & $\begin{array}{c}\text { Ciência e Tecnologia de } \\
\text { Alimentos }\end{array}$ & 1 & UNICAMP \\
\hline Ciências Biológicas & Biotecnologia & 3 & UFRJ, UFRGS, UFMG \\
\hline $\begin{array}{l}\text { Ciências Exatas } \\
\text { e da Terra }\end{array}$ & $\begin{array}{c}\text { Física e Química } \\
\text { Total de Programas }\end{array}$ & 12 & $\begin{array}{c}\text { RJ, CBPF, UFSCAR, USP, } \\
\text { UNICAMP, UFBA, UFPB, } \\
\text { UFPE, UFSM }\end{array}$ \\
\hline \multicolumn{2}{|c|}{ Totar, } \\
\hline
\end{tabular}

Elaboração do autor.

Fonte: DGP/CNPq e CAPES.

O total de possibilidades de formação de redes mais amplas em nanotecnologia revela-se promissor, sobretudo em relação às engenharias química e de materiais e às ciências exatas e da terra (física e química). Com relação ao complexo 
nano/biotecnologia foram registradas 41 ocorrências no DGP/CNPq. A CAPES, nesse sentido, criou o Programa Rede Nanobiotec-Brasil, para desenvolvimento de pesquisas cooperativas neste tema.

\section{Quadro 8 - Consolidado para Biotecnologia}

\begin{tabular}{|c|c|c|c|}
\hline Grande Área & $\begin{array}{c}\text { Área de Avaliação da } \\
\text { CAPES }\end{array}$ & $\begin{array}{c}\mathbf{N}^{\mathbf{0}} \text { de Programas } \\
\text { com Conceito } \\
\text { Igual ou } \\
\text { Superior a 5 }\end{array}$ & IES \\
\hline Engenharias & $\begin{array}{c}\text { Engenharia Química e } \\
\text { Engenharia de Materiais }\end{array}$ & 4 & $\begin{array}{c}\text { UFRJ, UFSCAR, USP, } \\
\text { UNICAMP }\end{array}$ \\
\hline Ciências da Saúde & Medicina e Farmácia & 3 & $\begin{array}{c}\text { UNICAMP, FIOCRUZ-RJ, } \\
\text { UNESP }\end{array}$ \\
\hline $\begin{array}{c}\text { Ciências Agrárias } \\
\text { (Genômica e Proteômica) }\end{array}$ & $\begin{array}{c}\text { Agronomia e Medicina } \\
\text { Veterinária }\end{array}$ & 13 & $\begin{array}{c}\text { UFV, UFLA, UFSM, } \\
\text { UFRRJ, UNESP, UENF, USP, } \\
\text { UFMG, UECE, UFRPE. } \\
\text { UNESP, UECE, UFV }\end{array}$ \\
\hline $\begin{array}{c}\text { Ciências Biológicas } \\
\text { (Proteomas } \\
\text { Genomas) }\end{array}$ & $\begin{array}{c}\text { Genética e Bioquímica } \\
\text { Ciências Exatas e da } \\
\text { Terra }\end{array}$ & 13 & $\begin{array}{c}\text { UCB-DF, UFMG, UNB, USP, } \\
\text { UFRJ, UFRGS, UNICAMP, } \\
\text { FIOCRUZ-RJ. UFMG, UFR, } \\
\text { UNIFESP, UNICAMP, USP }\end{array}$ \\
\hline \multicolumn{2}{|c|}{ Total de Programas } & 6 & $\begin{array}{c}\text { UNICAMP, UFRJ, UFMG, } \\
\text { UFSCAR, USP, UFSC }\end{array}$ \\
\hline \multicolumn{2}{|c|}{ Química } & 39 & \\
\hline
\end{tabular}

Elaboração do autor.

Fonte: DGP/CNPq e CAPES.

A evolução da biotecnologia nos últimos anos tem sido muito intensa graças aos esforços da CAPES na pós-graduação, apresentando um número significativo de possibilidades de formação de redes cooperativas de pós-graduação e pesquisa, sobretudo para aplicações na agricultura e saúde.

\section{Quadro 9 - Consolidado para Tecnologias da Informação e Comunicação (TIC)}

\begin{tabular}{|c|c|c|c|}
\hline Grande Área & $\begin{array}{c}\text { Área de Avaliação da } \\
\text { CAPES }\end{array}$ & $\begin{array}{c}\text { N. de PPGs com } \\
\text { Conceito Igual ou } \\
\text { Superior a 5 }\end{array}$ & IES \\
\hline Engenharias & Engenharia Elétrica & 9 & $\begin{array}{c}\text { USP, UFRJ, UFPE, UFSC, } \\
\text { UFMG, UNIFEI, UNICAMP, } \\
\text { UFRJ, UFSC }\end{array}$ \\
\hline Ciências da Saúde & Saúde Coletiva & 4 & UFRGS, USP, UERJ, UFBA \\
\hline Ciências Agrárias & Agronomia & 1 & USP \\
\hline $\begin{array}{c}\text { Ciências Exatas e } \\
\text { da Terra }\end{array}$ & Ciência da Computação & 6 & $\begin{array}{c}\text { USP, PUC-RJ, UFF, } \\
\text { UNICAMP, UFPE, UFRJ }\end{array}$ \\
\hline \multicolumn{2}{|c|}{ Total de Programas } & 20 & \\
\hline
\end{tabular}

Elaboração do autor.

Fonte: DGP/CNPq e CAPES. 
As informações contidas no Quadro 9 demonstram predominância em pesquisas referentes à tecnologia da informação e comunicação (TIC), desenvolvidas na região Sudeste do país. Dos vinte programas observados, seis das engenharias estão nessa região; $20 \%$ são programas da área de saúde coletiva; $5 \%$ das ciências agrárias e 30\% das ciências exatas e da terra, na área de computação.

\section{Quadro 10 - Consolidado para Energia}

\begin{tabular}{|c|c|c|c|}
\hline Grande Área & $\begin{array}{c}\text { Área de Conhecimento } \\
\text { da CAPES }\end{array}$ & $\begin{array}{c}\text { N. de Programas } \\
\text { com Conceito Igual } \\
\text { ou Superior a 5 }\end{array}$ & IES \\
\hline $\begin{array}{c}\text { Engenharias } \\
\text { (Petróleo e Gás) }\end{array}$ & $\begin{array}{c}\text { Engenharia Química, } \\
\text { Mecânica }\end{array}$ & 4 & $\begin{array}{c}\text { UFR, UFSC, UFRN, } \\
\text { UNICAMP }\end{array}$ \\
\hline $\begin{array}{c}\text { Ciências Agrárias (Etanol e } \\
\text { Biodiesel) }\end{array}$ & Agronomia & 2 & UFV, USP \\
\hline $\begin{array}{c}\text { Engenharias } \\
\text { (Energia Nuclear) }\end{array}$ & Engenharia Nuclear \\
\hline $\begin{array}{c}\text { Engenharias } \\
\text { (Células Combustíveis) }\end{array}$ & Engenharia Química & 3 & UFRJ, USP, UFPE \\
\hline $\begin{array}{c}\text { Engenharias } \\
\text { (Células Combustíveis) }\end{array}$ & Química & 4 & $\begin{array}{c}\text { UFBA, UFC, USP/RP, } \\
\text { UFRJ }\end{array}$ \\
\hline $\begin{array}{c}\text { Engenharias (Eólica) } \\
\text { Engenharia Elétrica }\end{array}$ & 9 & $\begin{array}{c}\text { UFRJ, UFCG, UFRGS, USP, } \\
\text { UFC, UFPE, UFRJ, PUC-RJ, } \\
\text { UFMG }\end{array}$ \\
\hline $\begin{array}{c}\text { Engenharias (Eólica) } \\
\text { (Aiências Agrárias }\end{array}$ & Engenharia Mecânica & 4 & $\begin{array}{c}\text { UFRJ, UFSC, UNICAMP, } \\
\text { UFU }\end{array}$ \\
\hline Total de Programas & 6 & $\begin{array}{c}\text { UFV, UFLA, USP, UFPB/ } \\
\text { AR, UFPR, UFRPE }\end{array}$ \\
\hline \multicolumn{2}{|c|}{ Agronomia } & 35 & \\
\hline
\end{tabular}

Elaboração do autor.

Fonte: DGP/CNPq e CAPES.

Conforme apresentado no Quadro 10, apesar da necessidade de desenvolvimento de formas alternativas de energia no Brasil, não há muitas lideranças para formação de redes mais densas de pesquisa, o que sugere que esforço de indução precisará ser feito para desenvolver linhas de pesquisa nesses temas no âmbito da pós-graduação. Com noventa ocorrências de grupos no DGP para energia eólica, há boas possibilidades de inserção dessa linha de pesquisa no ambiente da pós-graduação e de formação de redes nas áreas de elétrica e mecânica. No tema agroenergia, no qual o Brasil pretende ser liderança mundial, houve apenas 21 ocorrências no DGP/CNPq, sendo 11 na área de agronomia. 


\section{Quadro 11 - Oportunidades de Formação de Redes em Temas} Estratégicos nas Engenharias

\begin{tabular}{|c|c|c|c|}
\hline $\begin{array}{c}\text { Temas } \\
\text { Estratégicos }\end{array}$ & $\begin{array}{c}\text { Grupos de Pesquisa } \\
\text { N, NE e CO }\end{array}$ & $\begin{array}{c}\text { Ocorrências na Pós- } \\
\text {-Graduação com nota } \\
\text { igual ou superior a 5 }\end{array}$ & $\begin{array}{c}\text { Área de } \\
\text { Conhecimento da } \\
\text { CAPES }\end{array}$ \\
\hline Nanotecnologia & $\begin{array}{c}\text { UFC, UFPB, UFPA, } \\
\text { UNEB, UPE, UFAM, } \\
\text { UFBA, UFCG }\end{array}$ & $\begin{array}{c}\text { UFRJ, UFSC, USP, } \\
\text { UNICAMP, UFRGS, UFMG }\end{array}$ & Química e Materiais \\
\hline Biotecnologia & UFPA, IFBA, UFPE, UFT & $\begin{array}{c}\text { UFRJ, UFSCAR, USP, } \\
\text { UNICAMP }\end{array}$ & Química e Materiais \\
\hline $\begin{array}{c}\text { Tecnologia da } \\
\text { Informação e } \\
\text { Comunicação }\end{array}$ & $\begin{array}{c}\text { UFC, UFPE, UFT, IFBA, } \\
\text { IFRN, UAM, UFAM, } \\
\text { UNEB, UFBA, UNIFOR, } \\
\text { UnB }\end{array}$ & $\begin{array}{c}\text { USP, UFRJ, UFPE, UFSC, UNIFEI, UNICAMP, } \\
\text { UFRJ, UFSC }\end{array}$ & Elétrica \\
\hline
\end{tabular}

Elaboração do autor.

Fonte: DGP/CNPq e CAPES.

Em relação às engenharias (Quadro 11), há possibilidades de formação de redes mais amplas no estilo PROCAD NF para desenvolvimentos de pesquisa e pós-graduação nas tecnologias portadoras de futuro, envolvendo as áreas de engenharia química, de materiais e elétrica.

Quadro 12 - Oportunidades de Formação de Redes em Temas Estratégicos nas Ciências da Saúde

\begin{tabular}{|c|c|c|c|}
\hline Temas Estratégicos & $\begin{array}{c}\text { Grupos de Pesquisa } \\
\text { N, NE e CO }\end{array}$ & $\begin{array}{c}\text { Ocorrências na Pós- } \\
\text {-Graduação com nota } \\
\text { igual ou superior a 5 }\end{array}$ & $\begin{array}{c}\text { Área de } \\
\text { Conhecimento } \\
\text { da Capes }\end{array}$ \\
\hline Biotecnologia & UFG, UFRN, UFBA & UNESP & Farmácia \\
\hline Biotecnologia & UNEB, UnB, UFRN, UFMA & UNICAMP, FIOCRUZ-RJ & Medicina \\
\hline Nanotecnologia & $\begin{array}{c}\text { UFPE, UnB, UEPB, UFAL, } \\
\text { UFG }\end{array}$ & UFRGS, UNESP/Ar & Farmácia \\
\hline $\begin{array}{c}\text { Tecnologia da } \\
\text { Informação e } \\
\text { Comunicação }\end{array}$ & UFC, UFPB, UnB, UFBA & $\begin{array}{c}\text { UFRGS, FIOCRUZ-RJ, UERJ, } \\
\text { USP, UFBA }\end{array}$ & Saúde Coletiva \\
\hline
\end{tabular}

Elaboração do autor.

Fonte: DGP/CNPq e CAPES.

O Quadro 12 mostra outras possibilidades de formação de redes em biotecnologia, além daquelas relacionadas à agricultura e que há possibilidade de, pelo menos, um projeto de cooperação no estilo do PROCAD na área de farmácia, promissora para aplicações da nanotecnologia. Além disso, há possibilidade de aplicação das TICs em saúde pública. 
Quadro 13 - Oportunidades de Formação de Redes em Temas Estratégicos nas Ciências Agrárias

\begin{tabular}{|c|c|c|c|}
\hline Temas Estratégicos & $\begin{array}{c}\text { Grupos de Pesquisa } \\
\text { N, NE e CO }\end{array}$ & $\begin{array}{c}\text { Ocorrências na Pós- } \\
\text {-Graduação com nota } \\
\text { igual ou superior a 5 }\end{array}$ & $\begin{array}{c}\text { Área de } \\
\text { Conhecimento da } \\
\text { CAPES }\end{array}$ \\
\hline Nanotecnologia & UFPE, UFC, UnB & UNICAMP & $\begin{array}{c}\text { Alimentos, Pesca, } \\
\text { Florestal }\end{array}$ \\
\hline $\begin{array}{c}\text { Tecnologia da } \\
\text { Informação e } \\
\text { Comunicação }\end{array}$ & UFMT & USP & Ciências Agrárias \\
\hline Informática & $\begin{array}{c}\text { UFMA, UFRN, UFMT, } \\
\text { UFAL }\end{array}$ & UNESP, UFV & Agronomia \\
\hline
\end{tabular}

Elaboração do autor.

Fonte: DGP/CNPq e CAPES.

$\mathrm{Na}$ área de aplicações da biotecnologia na agricultura, as possibilidades de formação de redes cooperativas são muito amplas e já há esforços significativos apoiados pela CAPES e pelo CNPq, a exemplo da Rede Nordeste de Biotecnologia (RENORBIO). Assim, a opção adotada nesta pesquisa foi a de explorar temas específicos de aplicação na agricultura também mencionados no Livro Azul da $4^{a}$ CNCTI, conforme mostra o Quadro 13.

Quadro 14 - Outras possibilidades de Formação de Redes em Temas Estratégicos nas Ciências Agrárias

\begin{tabular}{|c|c|c|c|}
\hline $\begin{array}{c}\text { Temas } \\
\text { Estratégicos }\end{array}$ & $\begin{array}{c}\text { Grupos de Pesquisa } \\
\text { N, NE e CO }\end{array}$ & $\begin{array}{c}\text { Ocorrências na Pós- } \\
\text {-Graduação com nota } \\
\text { igual ou superior a 5 }\end{array}$ & $\begin{array}{c}\text { Área de } \\
\text { Conhecimento } \\
\text { da CAPES }\end{array}$ \\
\hline Genômica & $\begin{array}{c}\text { UFMT, UFMA, UFC, UECE, } \\
\text { UFRPE, UFPE, UnB. }\end{array}$ & $\begin{array}{c}\text { UFV, UFLA, UFSM, } \\
\text { UFRRJ, UNESP, UENF, USP, } \\
\text { UFMG, UECE, UFRPE. }\end{array}$ & $\begin{array}{c}\text { Agronomia e } \\
\text { Veterinária }\end{array}$ \\
\hline Proteômica & UFC, UECE, UFRPE, UFPE, & UNESP, UECE, UFV, & Veterinária \\
\hline $\begin{array}{c}\text { Agricultura } \\
\text { Familiar }\end{array}$ & $\begin{array}{c}\text { UFAL, UFG, UFT, UNEMAT, UFMT, } \\
\text { UESB, UFR, UFERSA, UFPE, UFC, } \\
\text { UnB, UFP, UEMA, UFAM }\end{array}$ & $\begin{array}{c}\text { UEL, UNESP, UFV, UFSM, } \\
\text { UFERSA }\end{array}$ & Agronomia \\
\hline $\begin{array}{c}\text { Agricultura de } \\
\text { Precisão }\end{array}$ & UFMT, UFG, UFRN, UFGD & $\begin{array}{c}\text { UEL, UFU, UFLA, UFSM, } \\
\text { UFRGS }\end{array}$ & Agronomia \\
\hline $\begin{array}{c}\text { Etanol e } \\
\text { Biodiesel }\end{array}$ & UFGD, UFAL, UFMA, UNEB, & UFV, USP & Agronomia \\
\hline
\end{tabular}

Elaboração do autor.

Fonte: DGP/CNPq e CAPES.

Com relação à agroenergia, embora com baixa inserção na pós-graduação, foram encontrados 21 grupos de pesquisa no país que poderiam formar redes sob a liderança de programas de química e agronomia. 
Quadro 15 - Oportunidades de Formação de Redes em Temas Estratégicos nas Ciências Biológicas

\begin{tabular}{|c|c|c|c|}
\hline $\begin{array}{c}\text { Temas } \\
\text { Estratégicos }\end{array}$ & $\begin{array}{c}\text { Grupos de Pesquisa } \\
\text { N, NE e CO }\end{array}$ & $\begin{array}{l}\text { Ocorrências na Pós- } \\
\text {-Graduação com nota } \\
\text { igual ou superior a } 5\end{array}$ & $\begin{array}{c}\text { Área de } \\
\text { Conhecimento da } \\
\text { CAPES }\end{array}$ \\
\hline Genoma & $\begin{array}{c}\text { UCB-DF, UFAM, UFBA, UFPB, } \\
\text { UNB, } \\
\text { UFMA, UFRN, UFPE, UFG }\end{array}$ & $\begin{array}{l}\text { UCB-DF, UFMG, UNB, USP, } \\
\text { UFRJ, UFRGS, UNICAMP, } \\
\text { FIOCRUZ-RJ }\end{array}$ & $\begin{array}{l}\text { Genética e } \\
\text { Bioquímica }\end{array}$ \\
\hline Proteoma & $\begin{array}{l}\text { UCB-DF, UFAM, INPA, } \\
\text { FMTAM, UFRN }\end{array}$ & $\begin{array}{l}\text { UFMG, UFRJ, UNIFESP, } \\
\text { UNICAMP, USP } \\
\end{array}$ & $\begin{array}{l}\text { Genética e } \\
\text { Bioquímica }\end{array}$ \\
\hline Nanotecnologia & UFPI, UFAC, UFPE & UFRJ, UFRGS, UFMG & Ciências Biológicas \\
\hline Bioinformática & $\begin{array}{l}\text { UCB-DF, UFERSA, UFBA, } \\
\text { UFPE, UECE, } \\
\text { UFC, UFPB, UNIVASF, UFRN, } \\
\text { UFMA, UFRPE, UFPA, UFAL, } \\
\text { UEFS }\end{array}$ & $\begin{array}{l}\text { UFRJ, UFRGS, UNICAMP, } \\
\text { USP, UFMG, FIOCRUZ-RJ. }\end{array}$ & Ciências Biológicas \\
\hline
\end{tabular}

Elaboração do autor.

Fonte: DGP/CNPq e CAPES.

Não houve ocorrências em relação às TIC. Genética e bioquímica no âmbito das ciências biológicas são temas estratégicos com significativas possibilidades para formação de redes.

\section{Quadro 16 - Oportunidades de Formação de Redes em Temas Estratégicos nas Áreas das Ciências Exatas e da Terra}

\begin{tabular}{|c|c|c|c|}
\hline $\begin{array}{c}\text { Temas } \\
\text { Estratégicos }\end{array}$ & $\begin{array}{c}\text { Grupos de Pesquisa } \\
\text { N, NE e CO }\end{array}$ & $\begin{array}{c}\text { Ocorrências na } \\
\text { Pós-Graduação } \\
\text { com nota igual ou } \\
\text { superior a } 5\end{array}$ & $\begin{array}{c}\text { Área de } \\
\text { Conhecimento da } \\
\text { CAPES }\end{array}$ \\
\hline Biotecnologia & $\begin{array}{c}\text { FTC, UECE, UCDB, UFAL, } \\
\text { UFRR, IEPA, UEMA, } \\
\text { CESUMAR, UPE, UFC, UFAM, } \\
\text { UFAC, UFBA, UESB, UFMT, } \\
\text { UFPA, UNIR, UEA }\end{array}$ & $\begin{array}{c}\text { UNICAMP, UFRJ, } \\
\text { UFMG, UFSCAR, USP, } \\
\text { UFSC }\end{array}$ & Química \\
\hline Nanotecnologia & $\begin{array}{l}\text { UFBA, UEPA, UFC, UFPE, } \\
\text { UFPA, UFPI }\end{array}$ & $\begin{array}{l}\text { UFC, UFPR, UFRJ, } \\
\text { PUC-RJ, CBPF, } \\
\text { UFSCAR, USP, } \\
\text { UNICAMP, UFBA, } \\
\text { UFPB, UFPE, UFSM }\end{array}$ & Física e Química \\
\hline $\begin{array}{l}\text { Tecnologia da } \\
\text { Informação e } \\
\text { Comunicação }\end{array}$ & $\begin{array}{c}\text { MPEG, UFPE, UFAC, UFMT, } \\
\text { UCG, } \\
\text { SENAI-BA, CESUMAR, UFCG, } \\
\text { IFRN, UESPI, UFAM, UNICAP, } \\
\text { IFBA, UNAMA, UFRPE, UFMS }\end{array}$ & $\begin{array}{c}\text { USP, PUC-RJ, UFF, } \\
\text { UNICAMP, UFPE, UFRJ }\end{array}$ & $\begin{array}{l}\text { Ciência da } \\
\text { Computação }\end{array}$ \\
\hline
\end{tabular}

Elaboração do autor.

Fonte: DGP/CNPq e CAPES. 
Sem ocorrência no DGP em Geoinformática com Programa de Pós-Graduação na área de Computação com nota igual ou maior que cinco. Física, química e ciência da computação apresentam boas possibilidades de formação de redes cooperativas para desenvolvimento das tecnologias portadoras de futuro.

Os resultados apresentados nesta pesquisa mostram amplas oportunidades de formação de redes cooperativas de pós-graduação e pesquisa no estilo PROCAD $\mathrm{NF}$ nas áreas estratégicas e tecnologias portadoras de futuro, voltadas à redução dos desequilíbrios regionais.

\section{CONSIDERAÇÕES FINAIS}

\section{Avaliação de Progresso do PROCAD NF 2007}

Os resultados quantitativos e qualitativos obtidos na pesquisa foram comparados com os pareceres da comissão julgadora, quando da Avaliação Intermediária do Programa, a qual foi organizada para efeitos de renovação dos projetos aprovados nessa edição, resultando as seguintes conclusões:

- Há significativo consenso quanto à relevância do Programa para o propósito de desenvolver temas complexos e quanto a sua contribuição para redução dos desequilíbrios acadêmicos regionais e intrarregionais;

- A totalidade dos respondentes mostrou elevado grau de satisfação com o progresso de seus projetos e com a gestão do Programa pela CAPES, que recebeu elogios e uma crítica isolada, relacionada à flexibilidade operacional, com relação a algumas despesas de custeio;

- Há discrepância entre as atividades propostas e executadas quando da Avaliação Intermediária, o que pôde ser constatado pela existência de saldo remanescente ao final do segundo ano de execução dos projetos. Essa relação é justificada pela dificuldade de adequação entre o planejamento original contido nos projetos e as agendas dos docentes e discentes envolvidos;

- Essa avaliação de progresso é relevante para correção de rumos dos projetos, considerando que cada edição do Programa Novas Fronteiras tem duração estipulada de cinco anos;

- A produção de dissertações e artigos em coautoria mostrou resultados animadores, embora os especialistas que aprovaram a renovação dos projetos tenham consistentemente recomendado a intensificação dessas atividades e alertado em relação à qualidade de revistas e congressos para divulgação dos resultados;

- As atividades de pós-doutoramento não resultou tão expressiva, provavelmente pelas dificuldades de liberação dos docentes pesquisadores das instituições envolvidas, por períodos variáveis de um a 12 meses. 


\section{Oportunidades de formação de redes de cooperação nas áreas estratégicas e tecnologias portadoras de futuro}

Uma das principais contribuições desta pesquisa foi o mapeamento de oportunidades na formação de redes de cooperação acadêmica nas áreas estratégicas e tecnologias portadoras de futuro, envolvendo instituições do Norte, Nordeste e Centro-Oeste.

$\mathrm{Na}$ perspectiva de formação de redes, é fundamental a expansão de um programa de bolsas para estágio no Brasil, de fluxo contínuo, aberta a outros programas. Esse tipo de programa promove a interação entre grupos e laboratórios e permite o compartilhamento de infraestrutura entre grupos de pesquisa no país, o que viabiliza uma maior mobilidade de pesquisadores. Além disso, o objetivo desta pesquisa possibilitou o mapeamento e a organização das oportunidades de formação de redes com maior conectividade, ou seja, maior potencial de desempenho, resultando as seguintes conclusões:

Correlações com as Tecnologias Portadoras de Futuro:

Nanotecnologia

As possibilidades de formação de redes mais amplas, sobretudo em relação às engenharias química e de materiais são promissoras nas ciências exatas e da terra (física e química).

Biotecnologia

Apresenta número significativo de possibilidades de formação de redes cooperativas de pós-graduação e pesquisa, sobretudo para aplicações na agricultura e saúde.

\section{Tecnologia da Informação e Comunicação}

Há possibilidades de formação de redes de pesquisa mais densas em TIC, tanto envolvendo os programas da elétrica quanto das ciências da computação.

\section{Correlações com as áreas estratégicas}

A formação de redes cooperativas para exploração dos Recursos do Mar (Amazônia Azul) e a inserção desse tema nos programas de pós-graduação precisam ser intensificadas, considerando a ocorrência de apenas 14 grupos cadastrados no Diretório do $\mathrm{CNPq}$. Na área de engenharia oceânica, há somente um programa com nota igual ou superior a cinco, da Universidade Federal do Rio de Janeiro (UFRJ), contudo foram encontrados 38 grupos em biologia marinha, incluindo instituições do Nordeste. 
Em relação às tecnologias ambientais, necessariamente interdisciplinares em suas dimensões de saúde, energia e mudanças climáticas, foi identificada grande variedade de grupos de pesquisa cadastrados no Diretório do CNPq com amplas possibilidades de formação de redes cooperativas, cujos resultados são apresentados no Quadro 17.

\section{Quadro 17 - Ocorrências de Temas Estratégicos nos Grupos de Pesquisa do CNPq}

\begin{tabular}{|c|c|}
\hline Temas Estratégicos & Grupos no DGP \\
\hline Ambiente e Saúde & 441 \\
\hline Ambiente e Energia & 188 \\
\hline Mudanças Climáticas & 142 \\
\hline Ecologia & 1434 \\
\hline Ciências Ambientais & 72 \\
\hline Tecnologias Ambientais & 98 \\
\hline
\end{tabular}

Elaboração do autor. Fonte: DGP/CNPq.

\section{Engenharias}

Há possibilidades de formação de redes mais amplas com o envolvimento das áreas de engenharia química, de materiais e elétrica.

Saúde

Há possibilidades de formação de redes em biotecnologia, além daquelas relacionadas à agricultura. Além disso, há possibilidade, também, de aplicação das TIC em saúde pública.

\section{Agricultura}

Há possibilidades de formação de redes com aplicações da biotecnologia na agricultura. Assim como grupos de pesquisa poderiam formar redes sob a liderança de programas de química e agronomia em agroenergia.

\section{Ciências Biológicas}

Há possibilidades de formação de redes para desenvolvimentos das tecnologias portadoras de futuro com a contribuição das ciências exatas e da terra, sobretudo nas áreas de bioquímica e genética, nas linhas de proteômica, genômica para aplicações na saúde e agricultura. 


\section{Ciências Exatas e da Terra}

Áreas como física, química e ciência da computação apresentam boas possibilidades de formação de redes cooperativas para desenvolvimento das tecnologias portadoras de futuro, bem como em temas emergentes de investigação científica, voltados à redução dos desequilíbrios regionais.

\section{Sugestões}

O Programa PROCAD é uma estratégia da CAPES que tem contribuído para a realização de pesquisas de alta qualidade e formação de pessoal qualificado, mediante a realização de investimentos voltados ao desenvolvimento de projetos cooperativos e formação de redes, de acordo com o propósito de redução das disparidades regionais do país.

O propósito da CAPES é que todos os programas de pós-graduação com conceitos três e quatro, das regiões Norte, Nordeste e Centro-Oeste, devam ter, ao menos, um projeto $\mathrm{PROCAD}$, tendo em vista objetivos de estímulo à pós-graduação, a mobilidade docente e discente e a fixação de pesquisadores doutores nessas regiões.

Os estudos já produzidos pelo Centro de Gestão e Estudos Estratégicos (CGEE) e pela própria CAPES oferecem bases sólidas para indução de formação de redes cooperativas de pesquisa para desenvolvimento das áreas estratégicas e das tecnologias portadoras de futuro.

Uma das tecnologias mais promissoras de pesquisa está relacionada à nanotecnologia, considerando que esta se direciona em grande medida ao entendimento e à criação de novos materiais, processos e sistemas que explorem novas propriedades nessa área. A aplicação de nanotecnologia tem sido observada em produtos voltados para o consumidor, destacando-se a fabricação de cosméticos, artigos de vestuário, tintas e vernizes e eletrodomésticos.

Para estudos futuros, os autores sugerem a realização de trabalhos semelhantes a respeito das demais edições e uma pesquisa envolvendo todos os atuais projetos do $\mathrm{PRO}-$ $\mathrm{CAD}$ para formação das redes, cujas possibilidades foram identificadas nesta pesquisa.

Considerando que a cooperação entre os grupos de pesquisa promove, principalmente, uma ambiência acadêmica favorável à formação pós-graduada, é válido confirmar o progresso do Programa PROCAD NF 2007 como instrumento que contribui para o equilibrio regional e o desenvolvimento do país, de modo que o torne um Brasil competitivo.

\section{REFERÊNCIAS}

BALANCiERI, Renato et al. A análise de redes de colaboração científica sob as novas tecnologias de informação e comunicação: um estudo na Plataforma Lattes. Ciência da 
Informação, Brasília, 2005. Disponível em: <http://revista.ibict.br/index.php/ciinf/ article/view/619/551>. Acesso em: mar. 2010.

BEAVER, Donald. Studies in scientific collaboration: part III: professionalization and the natural history of modern scientific co-authorship. Scientometrics, v. 1, p. 231245, 1979.

Disponível em: <http://www.springerlink.com/content/w12k65423p331v75/>. Acesso em: dez. 2010.

Brasil. Ministério da Ciência e Tecnologia (2010). Livro Azul da $4^{a}$ Conferência Nacional de Ciência e Tecnologia e Inovação para o Desenvolvimento Sustentável. 2010. Brasília: MCT/CGEE. 99p.

. Conselho Nacional de Desenvolvimento Científico (CNPq). Diretório dos Grupos de Pesquisa. 2011. Disponível em: <http://dgp.cnpq.br/buscagrupo/>. Acesso em: mar. 2011.

. Centro de Gestão e Estudos Estratégicos (CGEE). Associação Nacional de Pesquisa e Desenvolvimento das Empresas Inovadoras. Formação de recursos humanos em áreas estratégicas de ciência tecnologia e Inovação. 2010. Disponível em: <www.cgee. org.br>. Acesso em: nov. 2010.

Brasil. Ministério da Educação. Coordenação de Aperfeiçoamento de Pessoal de Nível Superior (CAPES). Plano Nacional de Pós-Graduação 2005-2010. Brasília: CAPES, 2005, 262p. Disponível em: <http://www.capes.gov.br/sobre-a-capes/planonacional-de-pos-graduacao $>$. Acesso em: out. 2010.

Avaliação Trienal 2010. Brasília: Capes, 2010. Disponível em: <http:// trienal.capes.gov.br/wp-content/uploads/2010/12/relat\%C3\%B3rio-geral-dosresultados-finais-da-avalia\%C3\%A7\%C3\%A3o-2010.pdf>. Acesso em: nov. 2010.

Brasil. Ministério da Fazenda. Secretaria do Tesouro Nacional (1997). Instrução Normativa n. 01, de 15 jan. Art. $8^{\circ}$, Inciso II, que dispõe a celebração de convênios de natureza financeira que tenham por objeto a execução de projetos ou realização de eventos e dá outras providências. Diário Oficial da União, Brasília, 31 jan. 1997. Disponível em: <http://www.tesouro.fazenda.gov.br/legislacao/download/ contabilidade/in1_97.pdf>. Acesso em: mar. 2011.

Brasil. Ministério do Desenvolvimento, Indústria e Comércio Exterior. Agência Brasileira de Desenvolvimento Industrial. Sondagem de inovação. Brasília, 2010, p. 42.

Brasil. Ministério do Planejamento, Orçamento e Gestão. Ministério da Fazenda. Ministério do Controle e da Transparência. Portaria Interministerial n. 127, de 29 mai., que dispõe sobre as normas relativas às transferências de recursos da União, mediante convênios e contratos de repasse. Diário Oficial da União, Brasília, 30 maio 2008. Disponível em: <http://www.tesouro.fazenda.gov.br/legislacao/download/ contabilidade/Portaria_127Int_Convenio.pdf >. Acesso em: mar. 2011. 
Gatti, Bernadete A. Estudos quantitativos em educação. Educação e Pesquisa, São Paulo, v. 30, n. 1, p. 11-30, jan./abr., 2004. Disponível em: <http://www.scielo.br/ pdf/ep/v30n1/a02v30n1.pdf>. Acesso em: mar. 2011.

Guimarães, Jorge. Presidente da CAPES diz que crise não afeta investimentos em mestrado e doutorado. FAPESPA. Revista Digital, Pará, 24 nov. 2008. Disponível em: <http://www.fapespa.pa.gov.br/?q=node/573>. Acesso em: jan. 2010.

Guimarães, Reinaldo. O futuro da pós-graduação: avaliando a avaliação. Revista Brasileira de Pós-Graduação [RBPG]. Notas para o seminário de comemoração do 55º aniversário da CAPES. Brasília: Capes, v. 4, n. 8, p. 282-292, 2007.

Price, Derek. Little science, big science. New Cork: Columbia University Press, 1963. STORER, Norman W. The internationality of science and the nationality of scientists. International Science Journal, v. 22, p. 87-104, 1970.

Subramanyam, Krishnappa. Bibliometric study of research collaboration: a review. Journal of Information Science, v. 6, p. 33-38, 1983. Disponível em: <http://jis.sagepub. com/content/6/1/33.refs >. Acesso em: set. 2010.

WeIsz, Joel; Roco, Mihail C. Redes de pesquisa e educação em engenharia nas Américas. Rio de Janeiro: FINEP, 1996.

\section{SOBRE OS AUTORES}

Dayse Benigna Bernardo Araujo Gomes é assistente em ciência e tecnologia da Coordenação de Aperfeiçoamento de Pessoal de Nível Superior (CAPES) e doutoranda em educação em ciências pela Universidade Federal do Rio Grande do Sul (UFRGS).

E-mail: dayse.gomes@capes.gov.br

Ivan Rocha Neto é PhD em eletrônica pela Universidade de Kent, em Canterbury, no Reino Unido. Professor da Universidade Católica de Brasília (UCB).

E-mail: neto-ivan@hotmail.com 


\title{
DAYSE BENIGNA BERNARDO ARAUJO GOMES E IVAN ROCHA NETO
}

\begin{abstract}
Avaliação de progresso do Programa Nacional de Cooperação Acadêmica - Novas Fronteiras - edição 2007 e oportunidades de formação de redes cooperativas nas áreas estratégicas e tecnologias portadoras de futuro
\end{abstract}

São apresentados resultados e estatística descritiva da consulta aos coordenadores de projetos para avaliar o progresso do Programa Nacional de Cooperação Acadêmica - Novas Fronteiras (2007). A metodologia foi de natureza qualitativa, inclusive comparando com os pareceres da comissão de especialistas que julgou a renovação dos projetos. Foram mapeadas as instituições com potencial para formação de redes de pesquisa em áreas estratégicas e tecnologias portadoras de futuro, conforme indicadas no Livro Azul da 4a CNCTI, mediante verificação de ocorrências no Diretório de Grupos de Pesquisa do Conselho Nacional de Desenvolvimento Científico e Tecnológico (CNPq) e de cursos recomendados pela Coordenação de Aperfeiçoamento de Pessoal de Nível Superior (CAPES), com conceitos iguais ou superiores a cinco com potencial para liderar redes cooperativas mais amplas.

Palavras-chave: avaliação de progresso; cooperação acadêmica; redes; Novas Fronteiras.

Assessment of progress of the National Academic Cooperation New Frontiers - 2007 edition and training opportunities for cooperative networks and technologies in strategic areas of future carrier

The results and descriptive statistics of an inquiry for project coordinators are presented for progress assessment of the National Program of Academic Cooperation - New Frontiers (2007). The methodology for assessment was of qualitative nature, including comparison with de assessments by the Committee of Specialists which recommended the renewal of projects. Institutions were mapped with potential for constitution of cooperative networks with focus on strategic areas and advanced technologies as indicated by the Blue Book from the 4th CNCTI through searches in the Directory of Research Groups of Conselho Nacional de Desenvolvimento Cientifico e Tecnologico (CNPq) matched with the graduate programs recommended by Coordenação de Aperfeiçoamento de Pessoal de Nivel Superior (CAPES) with grades equal or greater than five with network leadership potential.

Keywords: progress assessment; academic cooperation; networks; New Frontiers. 


\section{Evaluación del progreso de la Cooperación Académica Nacional - Nuevas Fronteras - edición 2007 y oportunidades de formación para las redes de cooperación y las tecnologías en áreas estratégicas de futuro}

Los resultados de la estadística descriptiva de una consulta a coordinadores de proyectos son presentados para evaluación de progreso of Programa Nacional de Cooperacion Académica - Nuevas Fronteras (2007). La metodología cualitativa consideró la comparación con los pareceres de los consultores especialistas que aprobaran la continuidad de los proyectos. Instituciones fueran mapeadas con potencial à la formación de redes de cooperación en las áreas estratégicas e tecnologías avanzadas indicadas en lo Libro Azul de la Cuarta Conferencia de Ciencia Tecnología y Innovación para lo Desarrollo Sustentable por medio de busca de ocurrencias no Directorio de Investigación del Conselho Nacional de Desenvolvimento Cientifico e Tecnológico (CNPq) para comparación con los programas de posgrado aprobados pela Coordenação de Aperfeiçoamento de Pessoal de Nivel Superior (CAPES) con grados mejores o iguales a cinco.

Palabras clave: evaluación de progreso; cooperación académica; redes; Nuevas Fronteras.

\section{MARCELO KROKOSCZ}

\section{Abordagem do plágio nas três melhores universidades de cada um de cinco continentes e do Brasil}

Este estudo visa identificar diferentes abordagens sobre o plágio; comparar as abordagens das melhores universidades mundiais com as universidades brasileiras; apresentar uma proposta de enfrentamento do plágio no Brasil. Realizou-se uma pesquisa descritiva documental com uma amostra não probabilística intencional extraída do Webometrics Ranking of World Universities. Constatou-se que nas universidades da Oceania, Europa e América o plágio é abordado de forma diversificada e abrangente, envolvendo medidas institucionais, preventivas, diagnósticas e corretivas. Verificou-se que nas universidades brasileiras o assunto praticamente não é abordado. Propõe-se as seguintes ações: atuação institucional no desenvolvimento da integridade acadêmica; definição e divulgação de política institucional; apresentação de conteúdo relacionado ao plágio nas home page das universidades brasileiras; integração do estudo sobre escrita acadêmica e plágio em matéria específica da grade dos cursos superiores.

Palavras-chave: plágio; abordagem universitária; medidas de enfrentamento. 